\title{
Assessment of Pulmonary Function, Nutritional Status and Quality of Life of Elderly Men with COPD- A Pilot Study
}

\author{
Chaya S. K. ${ }^{1}$, Lokesh K. S. ${ }^{2}$, Renukadevi Mahadevan ${ }^{3}$, Jayaraj B. S. ${ }^{4}$
}

\author{
${ }^{1}$ Assistant Professor, Department of Pulmonary Medicine, JSS Medical College, JSS AHER, Mysuru, Karnataka, India. \\ ${ }^{2}$ Assistant Professor, Department of Pulmonary Medicine, JSS Medical College, JSS AHER, Mysuru, Karnataka, India. \\ ${ }^{3}$ Professor, Department of Physiotherapy, JSS College of Physiotherapy, Mysuru, Karnataka, India \\ ${ }^{4}$ Professor, Department of Pulmonary Medicine, JSS Medical College, JSS AHER, Mysuru, Karnataka, India
}

\section{ABSTRACT}

\section{BACKGROUND}

Chronic obstructive pulmonary disease (COPD) is characterized by progressive airflow limitation that is not fully reversible. COPD has important extrapulmonary manifestations such as weight loss, skeletal muscle dysfunction, oxidative stress etc that can lead to deterioration in the nutritional, functional and social status. The objectives of the current study were to assess the pulmonary function, nutritional status \& quality of life of elderly subjects with COPD and to evaluate the association between them in elderly subjects with COPD.

\section{METHODS}

Elderly male subjects $(n=36)$ with stable COPD visiting the outpatient department were assessed for nutritional status using Mini Nutritional Assessment-Short Form, lung function by spirometry, severity of dyspnoea, exercise capacity, health related quality of life and serum haemoglobin levels, using convenient sampling. Subjects were classified based on their nutritional status, stage of COPD and dyspnoea and were evaluated for association between the parameters.

\section{RESULTS}

Overall, 36 subjects were included in this pilot study. Fourteen subjects were at risk of malnutrition and 22 of them were malnourished. Decreased food intake was present in 15 subjects and gastrointestinal symptoms in 16 subjects. Majority of the subjects had moderate to severe COPD (88.9\%). 21 subjects reported a perceived dyspnoea score of 3 . Subjects with severe COPD had lower six-minute walk distance, and BMI and significantly higher dyspnoea score compared to subjects with moderate COPD. The lung function of subjects was found to decrease significantly with increase in severity of dyspnoea (p-value: \% of FEV $1-0.001, \%$ of FVC- 0.026). Significant positive correlation was found between BMI, percentage of body weight and lung function parameters.

\section{CONCLUSIONS}

Majority of the subjects were found to be malnourished, and the reduction in food intake in a significant proportion of them was due to GI symptoms. BMI was positively associated with lung function. The severity of dyspnoea was found to negatively impact the health-related quality of life and BMI. Exercise capacity was influenced by the stage of COPD and severity of dyspnoea. Dyspnoea associated with COPD has important extrapulmonary effects.

\section{KEY WORDS}

Nutrition Status, Spirometry, Dyspnoea, Quality of Life, Walk Test

\author{
Corresponding Author: \\ Dr. Chaya S. K., \\ Department of Pulmonary Medicine, \\ JSS Medical College, JSS AHER, \\ Mysuru, Karnataka, India. \\ E-mail: chaya.sindaghatta@gmail.com
}

DOI: $10.14260 /$ jemds/2019/559

Financial or Other Competing Interests: None.

How to Cite This Article:

Chaya SK, Lokesh KS, Mahadevan R, et al. Assessment of Pulmonary function, nutritional status and quality of life of elderly men with COPD- a pilot study. J. Evolution Med. Dent. Sci. 2019;8(32): 25682572, DOI: $10.14260 /$ jemds/2019/559

Submission 08-07-2019,

Peer Review 29-07-2019,

Acceptance 01-08-2019,

Published 12-08-2019. 


\section{BACKGROUND}

Chronic obstructive pulmonary disease (COPD) is characterized by persistent airflow limitation that is not fully reversible. ${ }^{1}$ The global burden of COPD as reported by the global burden of disease study, 2017 is 299 million cases, with $247 \%$ increase in the rates compared to the prevalence rate of 199 million in the year $1990 .{ }^{2}$ COPD is the third leading cause of death in the world in the year $2016 .{ }^{3}$ In India, the COPD prevalence rate is reported to be 55.3 million in the year 2016, with an increase in the number of individuals in the year 1990 by 27.2 million. COPD was ranked as the second leading cause of death and disability-adjusted life year (DALY) in India in the year 2016. ${ }^{4}$ COPD is a chronic inflammatory disease, and the inflammation is seen in the pulmonary and systemic components. Chronic inflammation is linked with the extrapulmonary manifestations, including weight loss, skeletal muscle dysfunction, cardiovascular disease, and osteoporosis. The systemic effects combined with the respiratory symptoms induce negative influence on exercise tolerance, nutritional status, health-related quality of life, and prognosis of the disease. ${ }^{5}$

The elderly population is at risk of developing malnutrition secondary to poor quality and quantity of diet consumed. The changes in physiological status, basal metabolic rate, lean body mass, digestive capacity, sensory abilities, mastication, functional status, and social status can precipitate malnutrition. Chronic illness and associated hospitalization can further increase the risk of nutritional inadequacy. ${ }^{6}$ Changes in lung physiology with aging is known to reduce lung function. ${ }^{7}$ The severity of airway obstruction in individuals with COPD combined with poor nutritional status, functional disability, and cognitive impairment can hamper the quality of life. ${ }^{8,9}$ Thus, the objectives of the current study were to assess the pulmonary function, nutritional status \& quality of life of elderly subjects with COPD and to evaluate the association between BMI, nutritional status, pulmonary function, dyspnoea, exercise capacity and health-related quality of life in elderly subjects with COPD.

\section{METHODS}

\section{Study Design}

The subjects were selected among the patients visiting the outpatient department of pulmonology for consultation after evaluation of their pulmonary function, using convenient sampling technique. Informed consent was obtained from the subjects after providing details on the purpose of the study, procedures, risks, benefits and rights of the subjects. Only stable subjects who were aged more than 60 years with well controlled symptoms and without exacerbations of COPD, were included in the study. After obtaining their informed consent. Clearance from the institutional human ethics committee of JSS Medical College was obtained (JSS/MC/PG/1971/2019-20). The study was carried out for a period of three months between January to March 2019. Spirometry was performed using Easy One Pro spirometer (ndd Medizintechnik, Zurich) by a trained nurse, according to the ATS guidelines. ${ }^{10}$ The subjects were graded for severity of COPD using the GOLD criteria. ${ }^{11}$ The subjects were categorized into various SES groups using their per capita income based on the updated BG Prasad scale for the year 2016.12 The nutritional status of the subjects was assessed using mini nutritional assessment- short form (MNA-SF), which is a validated tool, recommended for use in the geriatric population. ${ }^{13}$ The subjects were categorized into various groups based on BMI using cut-off's recommended for use in the South Asian population. ${ }^{14}$ The health-related quality of life was assessed using St. George's respiratory questionnaire. ${ }^{15}$ The severity of dyspnoea was evaluated using the MMRC dyspnoea scale ${ }^{10}$ and the exercise tolerance by 6-minute walk test. ${ }^{16}$ The data on the smoking habits, pattern, occupation, residence, and income using a structured questionnaire.

\section{Statistical Analysis}

The data are presented as mean and standard deviation or number and frequency as suitable. The independent samples t-test was used to measure the difference between the groups. A p-value of less than 0.05 was considered to be statistically significant. Pearson's correlation test was performed to evaluate the association between variables. The data obtained was analysed using SPSS version 19.0 for windows.

\section{RESULTS}

\section{Demographic Profile}

The demographic characteristics of the study population are presented in table no 1 . The study group consisted of 36 male subjects, and 18 of them of them were in the 70-79 years age group; 17 subjects were in the 60-69 years category. All the subjects were ex-smokers and the pack years ranged between 12 - 120 years. According to the modified BG Prasad's classification, 13 (36\%) subjects each belonged to the lower income group and lower-middle-income group. 10 (28\%) of them were categorized as an upper-income group. All the subjects reported sedentary level of physical activity, out of whom $8(22 \%)$ subjects reported very minimal physical activity restricted to movement in an indoor area.

\section{Clinical Status}

Majority of the subjects had moderate to severe stage of COPD. Severe dyspnoea (MMRC score- 3 ) was reported in 58\% of the subjects, 11 subjects had a perceived dyspnoea score of 2 and 4 of them had perceived dyspnoea score of 1.3 (8.3\%) subjects had mild COPD, 14 (38.9\%) of them had moderate COPD, 18 $(50 \%)$ of them had severe COPD and 1 had very severe COPD. Among the subjects, 2 of them had diabetes mellitus, 4 of them had hypertension, and 26 of them pulmonary arterial hypertension. Majority of the subjects $(n=24)$ were on inhaled drugs for the management of COPD. Among the subjects, 26 of them had a history of exacerbation in the previous year (Range 1-5). 11 subjects were anaemic, and 25 of them had normal haemoglobin. Elevated CRP (>5 mg/L) was found in 18 (50\%) subjects.

\section{Nutritional Status}

Classification of subjects based on South Asian BMI cut-offs, revealed 14 (39\%) subjects to be underweight, 14 subjects to have normal BMI (39\%), 5 (14\%) subjects to be overweight and $3(8 \%)$ of them to be obese. $14(38.9 \%)$ subjects were 
found to be at risk of malnutrition and $22(61.1 \%)$ of them were found to be malnourished after assessing using MNA-SF.

The nutritional status indicators, pulmonary function indicators, haemoglobin, quality of life scores, and 6-minute walk distance among the at risk and malnourished groups were compared. The data is presented in table no 2 . Malnourished subjects had lower BMI, percentage of IBW, lower $\mathrm{FVC}, \mathrm{FEV}_{1}$, and $\mathrm{FEV}_{1} / \mathrm{FVC}$ ratio compared to subjects at risk of malnutrition. The malnourished subjects had significantly lower MNA-SF score. Overall, 12 (33.3\%) subjects reported weight loss during the last three months, and the mean weight loss was found to be $3.6 \pm 2.5 \mathrm{kgs}$. Among the malnourished group, $15 / 22$ subjects reported moderate to a severe decrease in food intake. Overall, 16 subjects reported the presence of gastrointestinal symptoms such as lack of appetite, early satiety, or fatigue during eating as the reasons for altered food intake. Differences in total SGRQ score, symptom score, and impact score was observed between the groups. The mean dyspnoea severity score was $2.21 \pm 0.69$ and $2.18 \pm 0.59$ in the at risk and malnourished groups, respectively. All the malnourished subjects and majority of the subjects (10) who were at risk of malnutrition reported an experience of psychological stress, related to a hospital visit or admission in the past three months.

\section{Stage of Disease}

The nutritional status indicators and quality of life scores of subjects with moderate and severe COPD were compared to evaluate the impact of severity of the disease. The data is shown in table no 3. The Mean MNA-SF score, BMI, percentage of ideal body weight, distance covered in six minutes, percentage of predicted distance were lower in the severe COPD group. Quality of life among the groups appeared to be similar. Subjects with severe COPD had significantly higher exacerbations of 2.3 in the previous year compared to 0.7 in the moderate COPD group $(\mathrm{p}<0.001)$. The severity of dyspnoea as perceived by the subjects, was also found to be higher in subjects with severe COPD. Subjects with mild COPD and very severe COPD were excluded due to insufficient number in the sub-groups.

\section{Severity of Dyspnoea}

The subjects were classified based on the severity of dyspnoea, and comparisons were made among the subgroups on pulmonary function, BMI, quality of life scores, and exercise capacity. The data is presented int table no 4 . The majority $(58 \%)$ of the subjects had a dyspnoea score of 2 . The lung function indicators, BMI, percentage of ideal body weight, and exercise capacity indicators were found to decrease with increasing dyspnoea score. The SGRQ score increased with dyspnoea scores indicating lower quality of life in subjects with increasing severity of dyspnoea. Subjects with severe COPD had significantly higher level of perceived dyspnoea as assessed using MMRC scale. The correlation analysis of the selected clinical and nutritional parameters was analysed using Pearson's correlation coefficient test. The data is presented in table no 5. A significant positive correlation was found between BMI, percentage of body weight \& lung function indicators.

\begin{tabular}{|c|c|}
\hline Parameter & Mean \pm SD \\
\hline Age (years) & $69 \pm 5$ \\
\hline Pack-years & $43 \pm 33$ \\
\hline Per capita income (rupees) & $2677 \pm 1041$ \\
\hline Parameter & Number (\%) \\
\hline \multicolumn{2}{|c|}{ Work Status } \\
\hline Retired & $26(72.2)$ \\
\hline Active & $10(27.8)$ \\
\hline \multicolumn{2}{|c|}{ Area of Residence } \\
\hline Rural & $27(75)$ \\
\hline Urban & $9(25)$ \\
\hline \multicolumn{2}{|c|}{ Smoking Habits } \\
\hline Actively smoking & $10(27.8)$ \\
\hline Ex-smokers & $26(72.2)$ \\
\hline
\end{tabular}

\begin{tabular}{|c|c|c|}
\hline \multirow{2}{*}{ Parameters } & $\begin{array}{c}\text { At risk of } \\
\text { Malnutrition (n-14) }\end{array}$ & $\begin{array}{c}\text { Malnourished } \\
(\mathbf{n}-\mathbf{2 2})\end{array}$ \\
\cline { 2 - 3 } & Mean \pm SD & Mean \pm SD \\
\hline MNA score & $9 \pm 1^{*}$ & $6 \pm 1^{*}$ \\
\hline BMI (kg/m $\left.{ }^{2}\right)$ & $20.93 \pm 5.79$ & $19.32 \pm 2.85$ \\
\hline$\%$ of IBW & $81 \pm 11$ & $78.36 \pm 14.35$ \\
\hline Symptom score & $50 \pm 18$ & $59 \pm 16$ \\
\hline Activity score & $68 \pm 17$ & $69 \pm 21$ \\
\hline Impact score & $31 \pm 11$ & $35 \pm 12$ \\
\hline Total SGRQ score & $45 \pm 11$ & $49 \pm 13$ \\
\hline 6-minute walk distance $(\mathrm{m})$ & $419 \pm 128$ & $417 \pm 110$ \\
\hline$\%$ of predicted distance & $81.11 \pm 11$ & $78.36 \pm 14.35$ \\
\hline FVC $(\mathrm{L})$ & $2.09 \pm 0.67$ & $1.93 \pm 0.5$ \\
\hline$\%$ FVC & $72.50 \pm 23.2$ & $72.23 \pm 19.03$ \\
\hline FEV 1 (L) & $1.18 \pm 0.47$ & $1.08 \pm 0.36$ \\
\hline$\%$ FEV 1 & $53.80 \pm 21.5$ & $52.56 \pm 16.39$ \\
\hline FEV 1 FVC ratio & $0.62 \pm 0.38$ & $0.55 \pm 0.08$ \\
\hline Haemoglobin $(\mathrm{g} / \mathrm{dl})$ & $14 \pm 1.6$ & $13.6 \pm 1.9$ \\
\hline
\end{tabular}

*indicates p-value of $<0.01$ between groups.

MNA- mini nutritional assessment, BMI - body mass index, IBW - ideal body weight, SGRQ - St. George's respiratory questionnaire, FVC - Forced vital capacity,

$\mathrm{FEV}_{1}$ - Forced expiratory volume in 1 second

Table 2. Comparison of Nutritional and Clinical Parameters of Subjects Classified According to Nutritional Status

\begin{tabular}{|c|c|c|c|}
\hline Parameters & $\begin{array}{c}\text { Moderate } \\
\text { COPD (n-14) }\end{array}$ & $\begin{array}{c}\text { Severe } \\
\text { CoPD (n-18) }\end{array}$ & p-value \\
\hline MNA score & $6 \pm 1$ & $7 \pm 2$ & 0.159 \\
\hline BMI $\left(\mathrm{kg} / \mathrm{m}^{2}\right)$ & $20.42 \pm 2.81$ & $18.24 \pm 3.81$ & 0.074 \\
\hline \% of IBW & $85.71 \pm 11.82$ & $76.16 \pm 15.56$ & 0.058 \\
\hline Total SGRQ score & $48 \pm 15$ & $48 \pm 11$ & 0.988 \\
\hline 6-minute walk distance (m) & $457 \pm 134$ & $391 \pm 105$ & 0.142 \\
\hline \% of predicted distance & $81.81 \pm 13.78$ & $77.63 \pm 12.57$ & 0.385 \\
\hline MMRC dyspnoea score & $1.93 \pm 0.475$ & $2.44 \pm 0.511$ & $\mathbf{0 . 0 0 7}$ \\
\hline
\end{tabular}

MNA- mini nutritional assessment, BMI - body mass index, IBW - ideal body weight, SGRQ - St. George's respiratory questionnaire, MMRC- modified medical research council

Table 3. Comparison of Nutritional and Clinical Parameters of Subjects Classified According to the Severity of COPD

\begin{tabular}{|c|c|c|c|c|}
\hline $\begin{array}{l}\text { MMRC Dyspnoea } \\
\text { Score }\end{array}$ & $1(n-4)$ & $2(n-21)$ & $3(n-11)$ & $\begin{array}{c}\text { p- } \\
\text { Value }\end{array}$ \\
\hline FVC (L) & $2.42 \pm 0.23$ & $1.97 \pm 0.46$ & $1.87 \pm 0.63$ & 0.254 \\
\hline$\% \mathrm{FVC}$ & $91.75 \pm 10.78$ & $74.33 \pm 18.16$ & $61.45 \pm 21.75$ & 0.026 \\
\hline $\mathrm{FEV}_{1}(\mathrm{~L})$ & $1.62 \pm 0.12$ & $1.09 \pm 0.32$ & $0.99 \pm 0.49$ & 0.020 \\
\hline$\% \mathrm{FEV}_{1}$ & $81 \pm 10.49$ & $52.4 \pm 14.38$ & $44.11 \pm 17.91$ & 0.001 \\
\hline $\mathrm{FEV}_{1} / \mathrm{FVC}$ ratio & $0.68 \pm 0.05$ & $0.6 \pm 0.31$ & $0.51 \pm 0.09$ & 0.447 \\
\hline BMI $\left(\mathrm{kg} / \mathrm{m}^{2}\right)$ & 22.77 & 20.0 & .72 & 0.261 \\
\hline$\%$ of IBW & $96.75 \pm$ & $83.9 \pm$ & $78.27 \pm 14.63$ & 0.208 \\
\hline Symptom scor & & & & 0.728 \\
\hline Activity sco & & & $70 \pm$ & 0.497 \\
\hline Impact s & & 13 & $36 \pm 9$ & 0.140 \\
\hline Total SGRQ score & & $48 \pm$ & $50 \pm 8$ & 0.193 \\
\hline 6-minute walk distance $(\mathrm{m})$ & $438 \pm 50$ & $434 \pm 144$ & $418 \pm 115$ & 0.449 \\
\hline$\%$ of predicted distance & $86.25 \pm 7.98$ & $79.03 \pm 14.41$ & $77.69 \pm 11.83$ & 0.535 \\
\hline
\end{tabular}

BMI - body mass index, IBW - ideal body weight, SGRQ - St. George's respiratory questionnaire, FVC - Forced vital capacity, $\mathrm{FEV}_{1}$ - Forced expiratory volume in 1 second,

Table 4. Comparison of Nutritional and Clinical Parameters of Subjects Classified According to the Severity of Dyspnoea 


\begin{tabular}{|c|c|c|c|c|}
\hline Parameter & FVC & FEV $_{\mathbf{1}}$ & \% Post FVC & \% Post FEV $_{\mathbf{1}}$ \\
\hline Age & -0.074 & -0.194 & 0.113 & -0.015 \\
\hline MNA Score & 0.048 & -0.066 & -0.066 & -0.084 \\
\hline BMI & 0.251 & $0.401^{*}$ & $0.334^{*}$ & $0.428^{* *}$ \\
\hline \% of IBW & 0.218 & $0.375^{*}$ & $0.353^{*}$ & $0.443^{* *}$ \\
\hline MNA- mini nutritional assessment, BMI - body mass index, IBW - ideal body weight, \\
FVC - Forced vital capacity, FEV ${ }_{1}$ - Forced expiratory volume in 1 second \\
\hline \multicolumn{6}{|c|}{ Table 5. Correlation Analysis of Age, Nutritional Status Indicators } \\
and Lung Function \\
\hline
\end{tabular}

\section{DISCUSSION}

Malnutrition is one of the important extra pulmonary manifestations of COPD that has a negative effect on the disease prognosis. Under nutrition is known to exist in 25$40 \%$ of patients with COPD. ${ }^{17}$ The proportion of subjects with malnutrition in our study appears to be similar with reported values. Patients with weight loss are known to have poor respiratory mechanics and lower exercise capacity compared to patients with optimal body weight. Loss of body cell mass in the former is associated with the loss of respiratory muscle mass and diaphragm mass as well, which can lead to a reduction in both respiratory strength and endurance. ${ }^{18}$ The prevalence of patients with malnutrition is known to increase with disease severity. ${ }^{19}$ Skeletal muscle dysfunction is another important systemic manifestation seen in patients with COPD. Insufficient intake of nutrients, oxidative stress, chronic inflammation induced muscle protein breakdown, muscle atrophy are the causative factors of skeletal muscle dysfunction and can negatively impact the functional capacity of a patient with COPD, and the extent of the impact is dependent on the severity of disease. ${ }^{20,21}$ This trend was evident in our study when subjects with moderate and severe COPD were compared. Mitra et al., have reported a significant positive correlation between BMI and $\mathrm{FEV}_{1 .}{ }^{22}$ Shimray et al., have also reported a significant positive correlation between BMI and spirometry-based lung function measurements. ${ }^{23}$ $\mathrm{BMI}$ is associated with a poor prognosis on patients with COPD and is known to be an independent predictor of mortality 24 Results from the current study are in agreement with the positive association of BMI on lung function in subjects with COPD.

Dyspnoea during food intake is known to be one of the factors contributing to a reduction in food intake and in the long term, malnutrition. ${ }^{25}$ Dyspnoea is known to be the most dominant respiratory symptom often associated with negative consequences on the quality of life in subjects with COPD. Numerous studies have reported this association. Okutan et al. have reported a positive correlation between stage of COPD and dyspnoea scale scores $(<0.01)$ among 90 patients with stable COPD with a mean age of $68.5 \pm 10.9$ years. ${ }^{26}$ Higher dyspnoea was also associated with activity impairment and lower quality of life among 245 out of 768 patients with COPD. ${ }^{27}$ The presence of dyspnoea is reported to limit several daily activities as well as impair sleep in patients with COPD. Reduction in physical activity in order to avoid the development of dyspnoea has also been reported. ${ }^{28}$ CRP is an acute phase protein primarily known to be elevated in the presence of infection and in the presence of inflammation. CRP is also known to be induced by interleukin-6 (IL-6), an inflammatory mediator which is elevated in smokers and patients with COPD. CRP is associated with the processes related with IL- 6 and is considered as a systemic indicator of lung inflammation. ${ }^{29}$ Thus, elevated CRP may reflect alterations in metabolism patients with COPD. ${ }^{30}$

\section{CONCLUSIONS}

Although COPD is primarily a disease of the respiratory system, the systemic effects are varied and are important components that can modify the prognosis of the disease and other health-related aspects. In our study, the majority of subjects were found to be malnourished, and the state of malnutrition was identified with the use of MNA-SF. Problems associated with malnutrition were decreased food intake and the presence of GI symptoms. BMI was positively associated with lung function. Health-related quality of life decreased with increasing severity of dyspnoea, whereas exercise capacity was influenced by the stage of disease and severity of dyspnoea. The dyspnoea secondary to COPD was negatively associated with indicators of nutritional status, exercise capacity and health related quality of life in elderly male subjects with COPD.

\section{REFERENCES}

[1] Mirza S, Clay RD, Koslow MA, et al. COPD guidelines: a review of the 2018 GOLD report. Mayo Clinic Proceedings 2018;93(5):1488-502.

[2] Roth GA, Abate D, Abate KH, et al. Global, regional and national age-sex-specific mortality for 282 causes of death in 195 countries and territories, 1980-2017: a systematic analysis for the Global Burden of Disease Study 2017. The Lancet 2018;392(10159):1736-88.

[3] WHO, 2016. Top 10 causes of death. https://www.who.int/gho/mortality_burden_disease/ca uses_death/top_10/en/ accessed on 17.6.2019.

[4] Naghavi M, Abajobir AA, Abbafati C, et al. Global, regional and national age-sex specific mortality for 264 causes of death, 1980-2016: a systematic analysis for the Global Burden of Disease Study 2016. The Lancet 2017;16;390(10100):1151-210.

[5] Agustí A. Systemic effects of chronic obstructive pulmonary disease: what we know and what we don't know (but should). Proceedings of the American Thoracic Society 2007;4(7):522-5.

[6] Brownie S. Why are elderly individuals at risk of nutritional deficiency? International Journal of Nursing Practice 2006;12(2):110-18.

[7] Dyer C. The interaction of ageing and lung disease. Chronic Respiratory Disease 2012;9(1):63-7.

[8] Peruzza S, Sergi G, Vianello A, et al. Chronic obstructive pulmonary disease (COPD) in elderly subjects: impact on functional status and quality of life. Respir Med 2003;97(6):612-7.

[9] Rasheed S, Woods RT. Malnutrition and quality of life in older people: a systematic review and meta-analysis. Ageing Research Reviews 2013;12(2):561-6.

[10] Celli BR, MacNee WA, Agusti AA, et al. Standards for the diagnosis and treatment of patients with COPD: a summary of the ATS/ERS position paper. Eur Respir J 2004;23(6):932-46. 
[11] Gold PM. The 2007 GOLD Guidelines: a comprehensive care framework. Respiratory Care 2009;54(8):1040-9.

[12] Khairnar MR, Wadgave U, Shimpi PV. Updated BG Prasad socioeconomic classification for 2016. Journal of Indian Association of Public Health Dentistry 2016;14(4):46970.

[13] Guigoz Y. The Mini Nutritional Assessment (MNA®) review of the literature-what does it tell us? Journal of Nutrition Health and Aging 2006;10(6):466-87.

[14] Misra A. Ethnic-specific criteria for classification of body mass index: a perspective for Asian Indians and American Diabetes Association position statement. Diabetes Technology \& Therapeutics 2015;17(9):667-71.

[15] Jones PW, Quirk FH, Baveystock CM. The St George's respiratory questionnaire. Respir Med 1991;85(Suppl B):25-31.

[16] Enright PL. The six-minute walk test. Respiratory Care 2003;48(8):783-5.

[17] Itoh M, Tsuji T, Nemoto $K$, et al. Undernutrition in patients with COPD and its treatment. Nutrients 2013;5(4):131635.

[18] Ezzell L, Jensen GL. Malnutrition in chronic obstructive pulmonary disease. Am J Clin Nutr 2000;72(6):1415-6.

[19] Schols AM, Ferreira IM, Franssen FM, et al. Nutritional assessment and therapy in COPD: a European Respiratory Society statement. Eur Respir J 2014;44(6):1504-20.

[20] Gea J, Pascual S, Casadevall C, et al. Muscle dysfunction in chronic obstructive pulmonary disease: update on causes and biological findings. Journal of Thoracic Disease 2015;7(10):E418-E38.

[21] Barreiro E. Skeletal muscle dysfunction in COPD: novelties in the last decade. Arch Bronconeumol 2017;53(2):43-4.

[22] Mitra M, Ghosh S, Saha K, et al. A study of correlation between body mass index and GOLD staging of chronic obstructive pulmonary disease patients. The Journal of Association of Chest Physicians 2013;1(2):58-61.

[23] Shimray AJ, Kanan W, Singh WA, et al. Association body mass index and spirometric lung function in chronic obstructive pulmonary disease (COPD) patients attending RIMS Hospital, Manipur. Journal of Medical Society 2014;28(3):157-61.

[24] Landbo C, Prescott EV, Lange P, et al. Prognostic value of nutritional status in chronic obstructive pulmonary disease. Am J Respir Crit Care Med 1999;160(6):1856-61.

[25] Grönberg A, Slinde F, Engström CP, et al. Dietary problems in patients with severe chronic obstructive pulmonary disease. Journal of Human Nutrition and Dietetics 2005;18(6):445-52.

[26] Okutan O, Tas D, Demirer E, et al. Evaluation of quality of life with the chronic obstructive pulmonary disease assessment test in chronic obstructive pulmonary disease and the effect of dyspnoea on disease-specific quality of life in these patients. Yonsei Med J 2013;54(5):1214-9.

[27] Gruenberger JB, Vietri J, Keininger DL, et al. Greater dyspnoea is associated with lower health-related quality of life among European patients with COPD. International Journal of Chronic Obstructive Pulmonary Disease 2017;12:937-44

[28] Miravitlles M, Ribera A. Understanding the impact of symptoms on the burden of COPD. Respiratory research 2017;18(1):67-78.

[29] Dahl M, Vestbo J, Lange P, et al. C-reactive protein as a predictor of prognosis in chronic obstructive pulmonary disease. American Journal of Respiratory and Critical Care Medicine 2007;175(3):250-5.

[30] Broekhuizen R, Wouters EF, Creutzberg EC, et al. Raised CRP levels mark metabolic and functional impairment in advanced COPD. Thorax 2006;61(1):17-22. 